\title{
A Cost-Effectiveness Framework for COVID-19 Treatments for Hospitalized Patients in the United States
}

\author{
Daniel Sheinson · Joseph Dang · Anuj Shah · Yang Meng · \\ David Elsea $\cdot$ Stacey Kowal
}

Received: November 13, 2020 / Accepted: February 4, 2021 / Published online: February 27, 2021

(C) The Author(s) 2021

\begin{abstract}
Introduction: The COVID-19 pandemic is a global crisis impacting population health and the economy. We describe a cost-effectiveness framework for evaluating acute treatments for hospitalized patients with COVID-19, considering a broad spectrum of potential treatment profiles and perspectives within the US healthcare system to ensure incorporation of the most relevant clinical parameters, given evidence currently available.

Methods: A lifetime model, with a short-term acute care decision tree followed by a post-discharge three-state Markov cohort model, was developed to estimate the impact of a potential treatment relative to best supportive care (BSC) for patients hospitalized with COVID-19. The model included information on costs and resources across inpatient levels of care, use of mechanical ventilation, post-discharge morbidity from ventilation, and lifetime healthcare
\end{abstract}

Supplementary Information The online version contains supplementary material available at https:// doi.org/10.1007/s12325-021-01654-5.

D. Sheinson · J. Dang · A. Shah · S. Kowal ( $₫)$ Evidence for Access, Genentech, Inc, South San Francisco, CA, USA

e-mail: kowal.stacey@gene.com

Y. Meng · D. Elsea

Health Economics, BresMed Health Solutions, Las

Vegas, NV, USA and societal costs. Published literature informed clinical and treatment inputs, healthcare resource use, unit costs, and utilities. The potential health impacts and cost-effectiveness outcomes were assessed from US health payer, societal, and fee-for-service (FFS) payment model perspectives.

Results: Viewing results in aggregate, treatments that conferred at least a mortality benefit were likely to be cost-effective, as all deterministic and sensitivity analyses results fell far below willingness-to-pay thresholds using both a US health payer and FFS payment perspective, with and without societal costs included. In the base case, incremental cost-effectiveness ratios (ICER) ranged from $\$ 22,933$ from a health payer perspective using bundled payments to $\$ 8028$ from a societal perspective using a FFS payment model. Even with conservative assumptions on societal impact, inclusion of societal costs consistently produced ICERs $40-60 \%$ lower than ICERs for the payer perspective.

Conclusion: Effective COVID-19 treatments for hospitalized patients may not only reduce disease burden but also represent good value for the health system and society. Though data limitations remain, this cost-effectiveness framework expands beyond current models to include societal costs and post-discharge ventilation morbidity effects of potential COVID-19 treatments. 
Keywords: Coronavirus; Cost-effectiveness; COVID 19; Economic evaluation; Inpatient treatment; Productivity

\section{Key Summary Points}

Why carry out this study?

The coronavirus disease 2019 (COVID-19) pandemic is a global crisis impacting individual and population health and the economy more broadly.

As the treatment landscape continues to evolve, there is a need for a common costeffectiveness framework to ensure adherence to modeling best practices and incorporation of the most relevant clinical parameters when assessing the value of COVID-19 treatments.

We describe a cost-effectiveness framework for evaluating acute treatments for hospitalized patients with COVID-19, considering a broad spectrum of potential treatment profiles and perspectives within the US healthcare system.

\section{What was learned from the study?}

Viewing results in aggregate, we find that treatments that confer at least a mortality benefit are likely to be cost-effective, as all deterministic and sensitivity analyses results fell far below US willingness-to-pay thresholds from both a US health payer and societal perspective. Even with conservative assumptions on societal impact, we find that the societal perspective consistently produced ICERs that were $40-50 \%$ lower than ICERs for the health payer perspective.

Effective COVID-19 treatments for hospitalized patients may not only reduce disease burden but also represent good value for the health system.
We also demonstrate that, despite limited data available on the long-term impact of invasive mechanical ventilation and productivity of COVID-19 patients postdischarge, it is possible to estimate the cost-effectiveness of inpatient treatments for COVID-19 from a societal perspective using a conservative approach to help guide future decisions on allocation of healthcare resources.

\section{DIGITAL FEATURES}

This article is published with digital features, including a summary slide, to facilitate understanding of the article. To view digital features for this article go to https://doi.org/10.6084/ m9.figshare.13712821.

\section{INTRODUCTION}

The coronavirus disease 2019 (COVID-19) pandemic is a global crisis. As of November 3, 2020, the United States (USA) has the highest number of cases and deaths globally, with over 9 million confirmed cases and more than 231,000 deaths (70.77 deaths per 100,000) [1]. While information on the trajectory and burden of COVID-19 is constantly evolving, it is estimated that $20 \%$ of those infected require hospitalization, and of the adults hospitalized with COVID-19, 32\% required intensive care unit (ICU) admission and $19 \%$ received invasive mechanical ventilation [2-4]. Data on the long-term burden of COVID-19 is only just emerging, but existing research suggests that morbidity and mortality impacts will extend far past acute hospital stays $[5,6]$. Beyond the healthcare sector, the global economy is forecast to shrink by $5.2 \%$ in 2020 , and the COVID-19 pandemic is estimated to result in almost $\$ 8$ trillion in economic losses in the USA over the next decade $[7,8]$. Since COVID-19 was declared a national emergency, over 60 million initial unemployment claims have been filed as of the end of October, and the federal government has committed \$2.4 trillion to COVID-19 relief bills $[9,10]$. 


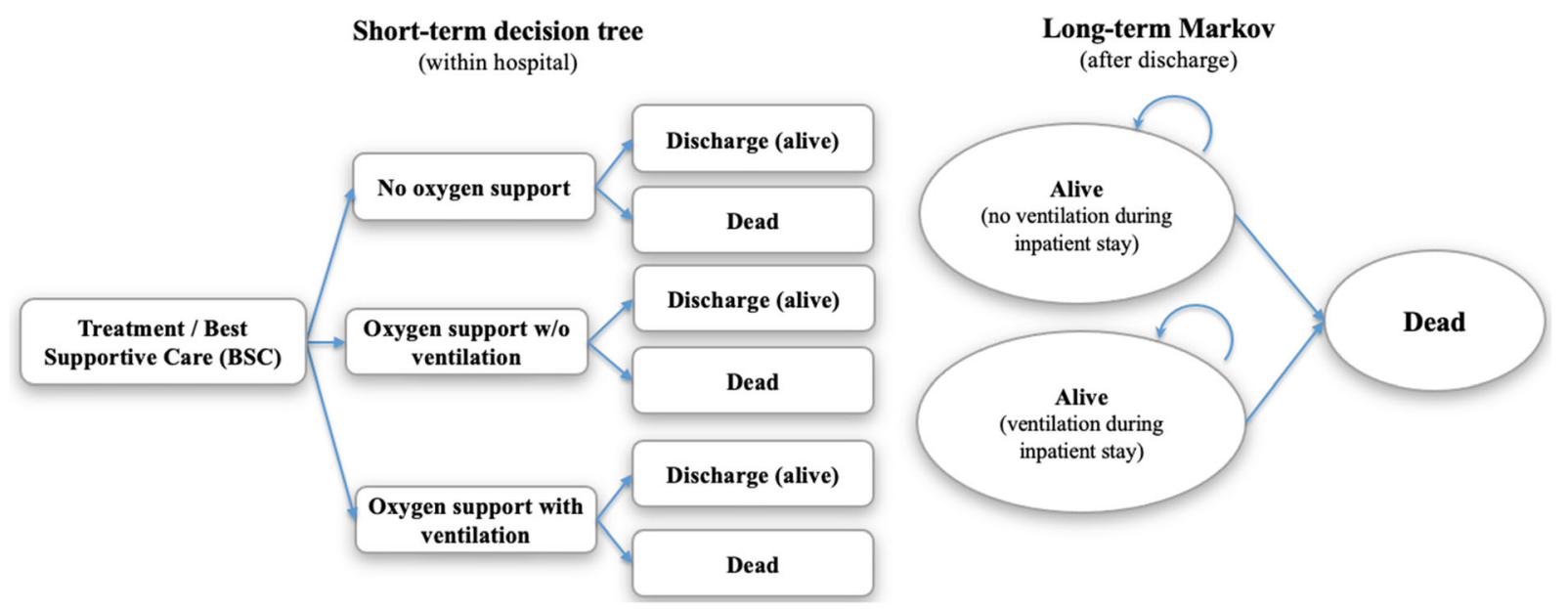

Fig. 1 Model structure. Patients in the "Alive (no ventilation during inpatient stay)" state comprise patients discharged alive from the "no oxygen support" and the "oxygen support without ventilation" states. Patients in the "Alive (ventilation during inpatient stay)" state represent

Given the growing health and economic impact of COVID-19, research into COVID-19 vaccines and treatments is moving at a rapid pace [11]. Decision-makers will need to quantify the value of new treatments to best allocate healthcare resources. Recent discussions on the value of COVID-19 treatments in the USA leverage cost-effectiveness analyses (CEA) to inform relative value and how to best maximize social welfare through evidence-based pricing decisions that balance optimizing access and incentivizing future innovation [12-15]. As the treatment landscape continues to evolve, understanding the independent and synergistic effects of potential COVID-19 treatments can aid in identifying the most important inputs for cost-effectiveness modeling and future data collection from clinical trials [16-18]. For potential COVID-19 treatments, understanding the effects on key outcomes (e.g., mortality, mechanical ventilation, duration of hospital stay), effects in patient subgroups (e.g., age, respiratory support required, disease severity, race/ethnicity), and the magnitude of clinical benefit will be necessary to best inform treatment and policy decisions $[19,20]$. However, given the various therapies currently in development for COVID-19 (e.g., antivirals, immunomodulators, blood-derived products), patients discharged alive from the "oxygen support with ventilation" state. Ventilation in the model refers to invasive mechanical ventilation. $\mathrm{BSC}=$ best supportive care; $\mathrm{w} / \mathrm{o}=$ without

there is a need for a common cost-effectiveness framework to ensure adherence to modeling best practices and incorporation of the most relevant clinical parameters.

Consistent with the themes in this current debate on the value of treatments during a pandemic, the Second Panel on Cost-Effectiveness in Health and Medicine recommended that assessments of new innovations present both a health payer and a societal perspective to support transparent decisions on allocation of healthcare resources [21, 22]. Despite these recommendations, recent CEAs of interventions for COVID-19 have either not incorporated a societal perspective or have reported a limited societal perspective based only on limited assumptions from other diseases [15, 23, 24]. A lack of peer-reviewed CEAs on COVID-19 inpatient treatments and data gaps in understanding societal and post-discharge impacts on health and cost outcomes stand as current barriers to informing evidence-based decisions on COVID19 treatment coverage and, ultimately, patient access.

The purpose of this study is to describe a cost-effectiveness framework for evaluating acute treatments for hospitalized patients with COVID-19 in the USA, according to current health economic modeling best practices 
Table 1 Utility and efficacy inputs

\begin{tabular}{lllll}
\hline Parameter & $\begin{array}{l}\text { Base } \\
\text { case }\end{array}$ & Distribution Lower-upper Reference
\end{tabular}

Efficacy inputs for treatment arm

Hospital level of acute care

Risk ratio for reduction in patients requiring mechanical $\quad 0.77 \quad 0.046$ Log-normal $\quad(0.70-0.84)$ ventilation

Hazard ratio for reduction in inpatient mortality for treated (vs BSC) by highest level of acute care received

Patients without oxygen support

Patients with oxygen support

Patients on mechanical ventilation
1.0
0.670 .093 Log-normal
(0.68-1.50)
$(0.56-0.80)$
$0.890 .081 \quad$ Log-normal
(0.76-1.04)

Ratio of length of stay for BSC (vs treated) by highest level of acute care among recovering patients

Patients without oxygen support

Patients with oxygen support

Patients on mechanical ventilation
$1.130 .051 \quad$ Log-normal
$(1.02-1.25)$
$1.24 \quad 0.036 \quad$ Log-normal
(1.15-1.33)
$1.23 \quad 0.063 \quad$ Log-normal
(1.09-1.39)

Utility inputs

US age-specific utility
$18-29$
$0.920 \quad 0.002$ Beta
(0.92-0.93)
30-39
$0.900 \quad 0.002$ Beta
(0.9-0.91)
40-49
$\begin{array}{lll}0.870 & 0.002 & \text { Beta }\end{array}$
(0.87-0.88)
50-59
$\begin{array}{lll}0.840 & 0.003 & \text { Beta }\end{array}$
$(0.84-0.85)$
60-69
$0.820 \quad 0.003$ Beta
$(0.82-0.83)$
$70-79$
$0.790 \quad 0.004$ Beta
$(0.78-0.8)$
$\geq 80$
$0.740 \quad 0.006$ Beta
$(0.72-0.75)$

[37]

Disutility during the hospitalization, by highest level of acute care received

\section{COVID-19 symptoms}

No oxygen support

Oxygen support without ventilation

Mechanical ventilation

$$
\begin{array}{lll}
0.270 & 0.300 & \text { Beta } \\
0.110 & 0.300 & \text { Beta } \\
0.360 & 0.300 & \text { Beta } \\
0.560 & 0.300 & \text { Beta }
\end{array}
$$

Post discharge disutility for patients requiring mechanical ventilation (applied for 5 years)
1 year
$0.130 \quad 0.013$ Beta
$(0.1-0.15)$
2 years
0.0670 .007 Beta
(0.05-0.08)
3 years
0.0620 .006 Beta
(0.05-0.07)
4 years
0.0260 .000 Beta
$(0.02-0.03)$
5 years
$0.024 \quad 0.000 \quad$ Beta
(0.02-0.03)

$[6,38]$
(0.00-0.95)

(0.00-1.00)

(0.00-0.96)

(0.03-0.99)

[24] 
Table 1 continued

\begin{tabular}{llllll}
\hline Parameter & $\begin{array}{c}\text { Base } \\
\text { case }\end{array}$ & SE & Distribution & Lower-upper Reference \\
\hline $\begin{array}{l}\text { Hazard ratio for post-discharge mortality for ventilated } \\
\text { patients vs general population (applied for 5 years) }\end{array}$ & 1.33 & 0.13 & Log-normal & $(1.09-1.62)$ & {$[36]$} \\
\hline
\end{tabular}

The risk ratio for reduction in patients requiring mechanical ventilation was applied to the proportion of patients who received mechanical ventilation later during their stay but were admitted to the non-ventilation states (11.36\%) and not to those who required ventilation at admission (18.59\%) (see Table 2). The final estimate of the proportions of patients by highest level of care received for the treatment arm was as follows: no oxygen support, 19.46\%; oxygen support w/o mechanical ventilation, $53.09 \%$; mechanical ventilation, $27.46 \%$. The detailed calculation of the base case efficacy parameters for the treatment arm is shown in Table 55 in the supplementary material

BSC $=$ best supportive care; COVID-19 = coronavirus disease 2019; SE = standard error; US = United States

[25-27]. Considering a broad spectrum of potential treatment profiles and perspectives within the US healthcare system-including a traditional health payer, a societal, and a feefor-service (FFS) payment model perspectiveallows for an understanding of cost-effectiveness under a range of scenarios but also aids in identifying important variables to help prioritize future data generation efforts.

\section{METHODS}

\section{Analytic Structure}

A cost-effectiveness model was developed in Microsoft Excel 2016 (Microsoft Corporation, Redmond, WA, USA) to estimate the impact of a potential treatment relative to best supportive care (BSC) for hospitalized patients with COVID-19. To best represent current knowledge of the COVID-19 patient experience in the USA, a lifetime model was used which included a short-term acute care decision tree followed by a post-discharge three-state Markov cohort model with an annual cycle length and halfcycle correction (Fig. 1). The model structure was chosen on the basis of a review of available COVID-19 inpatient treatment models in the public domain. Slight variation in model structures was observed given differences in study objective and data available at the time of development. However, all identified models combined an acute care decision tree followed by a lifetime Markov model to best capture differing timescales for the initial acute stay and lifetime aspects of the model $[15,28]$. The chosen model structure also reflected the nature of the randomized controlled trial (RCT) and real-world evidence to date, which was limited. While it is important to note that alternative model structures may emerge as evidence evolves on the impact of COVID-19, choices made around the model structure and input parameter values in this study were intended to be conservative with respect to downstream effects of COVID-19 that could potentially be avoided with beneficial treatment in the inpatient setting.

All costs and health effects were discounted at 3\% per year [21]. Key effectiveness measures included total life years and quality-adjusted life years (QALYs). Costs were expressed in 2020 US dollars (USD), and cost inputs were inflated using the medical care services component of the consumer price index [29]. A structured targeted literature review was conducted to inform model development and support parameterization. Published phase III clinical data was leveraged to inform the clinical profile of potential COVID-19 treatments and clinical inputs for BSC [19, 20, 30-33]. Further details of the literature review and development of the clinical profiles are specified in the supplementary material. This article does not contain any 
new studies with human or animal subjects performed by any of the authors.

The modeled population consisted of hospitalized patients with COVID-19 and an average age upon admission of 62.5 years, $64.2 \%$ of whom were male [30-32]. All patients entered the model in the decision tree (acute care) and the evolution of their inpatient stay was modeled on the basis of the highest level of oxygen support received during hospitalization (Table S1 in the supplementary material). Patients admitted in the non-oxygen support state or oxygen support without ventilation state could also go on to receive ventilation according to the probabilities specified in Table 2. Specifically, to best represent patients eligible for inpatient COVID-19 treatments, the final outcomes (e.g., length of stay [LOS], mortality, utilities) for the acute care model were based on the highest level of care received, as observed in clinical trials: hospitalized without oxygen support, hospitalized with oxygen support (but without mechanical ventilation), and hospitalized with mechanical ventilation.

Patients either died during their hospitalization or recovered, after which they entered the long-term Markov model in either alive (no ventilation during inpatient stay) or alive (ventilation during inpatient stay) states, depending on whether they progressed to mechanical ventilation while inpatient. Thereafter, patients in the alive (no ventilation during inpatient stay) state were assumed to have an annual probability of death similar to the general population, based on age and sex-adjusted US allcause life tables [34]. Patients discharged from the hospital after receiving mechanical ventilation (alive [ventilation during inpatient stay] state) were assumed to have an increased risk of morbidity and mortality compared to the general population. Notable model assumptions included no explicit estimation of treatment impact on overall healthcare system capacity, no inclusion of adverse event-related costs or disutilities, average age of patients recovered in the hospital the same as average age at admission, and no additional costs of drug administration.

\section{Defining the Treatment Arm}

The model assessed cost-effectiveness of a treatment arm for hospitalized COVID-19 patients versus BSC. The treatment arm was differentiated from BSC via modified input parameters affecting (1) the average LOS in the hospital (i.e., short-term decision tree part of the model); (2) the likelihood of receiving mechanical ventilation as the highest level of care during the hospital stay; and (3) the likelihood of death in the hospital. The base case clinical profile for the treatment arm was determined by taking the average between drug efficacy results from the two published clinical trials reporting 28-day outcomes at the time of model development, including dexamethasone (RECOVERY trial) and remdesivir (ACTT-1 trial) $[31,33]$ (Table S5 in the supplementary material). Although the WHO SOLIDARITY pre-print was available at the time of model development, it lacked detailed information by level of care at admission for several key variables [32]. The use of the RECOVERY and ACTT- 1 trials for efficacy inputs translated to a treatment arm with an assumed 23\% reduction in the hazard of progression to mechanical ventilation, a $10-25 \%$ increase in speed to recovery, and a $0-33 \%$ reduction in hazards of mortality, with ranges depending on the highest level of care received during the hospital stay (Table 1). To explore potential treatments whose benefits may depart from those observed in clinical trial populations to date, scenario analyses were generated in which the LOS and mechanical ventilation reductions were sequentially removed from the base case treatment profile.

\section{Clinical Inputs}

Clinical inputs, including the distribution of patients' highest level of oxygen support received, LOS by highest level of oxygen support, proportions recovering by highest level of oxygen support, and treatment efficacy by highest level of oxygen support were derived from published and pre-print clinical trials available at the time of model development and are shown in Tables 1 and 2. Results from 
Table 2 Resource use, best supportive care efficacy, and cost inputs

\begin{tabular}{llllll}
\hline Parameter & Base case & SE & Distribution & Lower-upper & Reference \\
\hline
\end{tabular}

Resource use inputs

Distribution of highest level of acute care at admission

\begin{tabular}{|c|c|c|c|c|c|}
\hline No oxygen support & $20.06 \%$ & $\mathrm{~N}=1751$ & Dirichlet & $(18.00-22.00 \%)$ & \\
\hline $\begin{array}{l}\text { Oxygen support but no mechanical } \\
\text { ventilation }\end{array}$ & $61.35 \%$ & $\mathrm{~N}=5355$ & Dirichlet & $(55.00-67.00 \%)$ & {$[31,33,55]$} \\
\hline Mechanical ventilation & $18.59 \%$ & $N=1623$ & Dirichlet & $(17.00-20.00 \%)$ & \\
\hline \multicolumn{6}{|l|}{ Inpatient characteristics for both arms } \\
\hline $\begin{array}{l}\text { Time to death for both arms (days, } \\
\text { all settings) }\end{array}$ & 15.00 & 1.50 & Log-normal & $(12.34-18.24)$ & Assumption \\
\hline $\begin{array}{l}\text { Mean age of patients discharged alive } \\
\text { from the hospital }\end{array}$ & 62.50 & 6.25 & Normal & $(50.25-74.75)$ & {$[31,33]$} \\
\hline $\begin{array}{l}\text { Mean age of patients dying within } \\
\text { the hospital }\end{array}$ & 78.00 & 7.80 & Log-normal & $(64.15-94.84)$ & {$[35]$} \\
\hline
\end{tabular}

Best supportive care efficacy-related inputs

Transition from no oxygen support or oxygen support without mechanical ventilation to mechanical ventilation

$\begin{array}{llllll}\begin{array}{l}\text { Proportion of patients receiving } \\ \text { mechanical ventilation among those }\end{array} & 11.36 \% & 1.14 \% & \text { Beta } & (9.00-14.00 \%) & {[33,55]} \\ \text { not receiving it at admission } & & & & & \\ \begin{array}{l}\text { Proportion of patients with oxygen } \\ \text { support at admission among those } \\ \text { transitioning to mechanical } \\ \text { ventilation }\end{array} & 93.18 \% & 9.32 \% & \text { Beta } & (66.00-100.00 \%) & {[33]}\end{array}$

Proportion recovering (surviving) during their inpatient stay by highest level of acute care for best supportive care

$\begin{array}{llllll}\text { No oxygen support } & 96.02 \% & 9.60 \% & \text { Beta } & (65.00-100.00 \%) & {[31,33,35]} \\ \begin{array}{l}\text { Oxygen support but no mechanical } \\ \text { ventilation }\end{array} & 84.04 \% & 8.40 \% & \text { Beta } & (64.00-97.00 \%) & {[31,33,55]} \\ \begin{array}{l}\text { Mechanical ventilation } \\ \text { Meta }\end{array} & 73.82 \% & 7.38 \% & \text { Beta } & (58.00-87.00 \%) & {[31,33,35]}\end{array}$

Length of stay by highest level of acute care for best supportive care among patients recovering (surviving) during their inpatient stay

\begin{tabular}{llllll} 
No oxygen support & 6.00 & 0.75 & Log-normal & $(4.70-7.66)$ & {$[33]$} \\
$\begin{array}{l}\text { Oxygen support but no mechanical } \\
\text { ventilation }\end{array}$ & 12.58 & 1.88 & Log-normal & $(9.41-16.82)$ & {$[33]$} \\
$\begin{array}{l}\text { Mechanical ventilation } \\
\text { Cost use inputs }\end{array}$ & 28.00 & 2.80 & Log-normal & $(23.03-34.05)$ & {$[33]$} \\
Inpatient costs & & & & & \\
\hline
\end{tabular}


Table 2 continued

\begin{tabular}{|c|c|c|c|c|c|}
\hline Parameter & Base case & SE & Distribution & Lower-upper & Reference \\
\hline $\begin{array}{l}\text { No oxygen support bundled payment } \\
\text { (DRG 179) }\end{array}$ & $\$ 8767.42$ & $\$ 1315.11$ & Gamma & $(\$ 6381.45-11,526.47)$ & {$[40,56]$} \\
\hline $\begin{array}{l}\text { Oxygen support without ventilation } \\
\text { bundled payment (DRG } 177 / 178 \text { ) }\end{array}$ & $\$ 13,282.61$ & $\$ 1992.39$ & Gamma & $(\$ 9667.87-17,462.56)$ & {$[40,56]$} \\
\hline $\begin{array}{l}\text { Mechanical ventilation bundled } \\
\text { payment (DRG 207) }\end{array}$ & $\$ 49,631.85$ & $\$ 7444.78$ & Gamma & $(\$ 36,125.00-65,250.65)$ & {$[40,56]$} \\
\hline No oxygen support per diem & $\$ 1571.54$ & $\$ 235.73$ & Gamma & $(\$ 1143.86-2066.09)$ & {$[30,56]$} \\
\hline $\begin{array}{l}\text { Oxygen support without ventilation } \\
\text { per diem }\end{array}$ & $\$ 1299.02$ & $\$ 194.85$ & Gamma & $(\$ 945.50-1707.81)$ & {$[30,56]$} \\
\hline Mechanical ventilation per diem & $\$ 2243.39$ & $\$ 336.51$ & Gamma & $(\$ 1632.87-2949.37)$ & {$[30,56]$} \\
\hline \multicolumn{6}{|c|}{ Annual healthcare costs by age after discharge } \\
\hline Age group $0-18$ & $\$ 4432.00$ & $\$ 443.20$ & Gamma & $(\$ 3563.34-5300.66)$ & {$[41]$} \\
\hline Age group 19-44 & $\$ 5741.00$ & $\$ 574.10$ & Gamma & $(\$ 4615.78-6866.22)$ & {$[41]$} \\
\hline Age group 45-64 & $\$ 12,073.00$ & $\$ 1207.30$ & Gamma & $(\$ 9706.74-14,439.26)$ & {$[41]$} \\
\hline Age group $65-84$ & $\$ 20,071.00$ & $\$ 2007.10$ & Gamma & $(\$ 16,137.16-24,004.84)$ & {$[41]$} \\
\hline Age group $85+$ & $\$ 38,900.00$ & $\$ 3890.00$ & Gamma & $(\$ 31,275.74-46,524.26)$ & {$[41]$} \\
\hline $\begin{array}{l}\text { Additional } 1 \text { year costs for patients } \\
\text { discharged with mechanical } \\
\text { ventilation }\end{array}$ & $\$ 7858.99$ & $\$ 785.90$ & Gamma & $(\$ 6318.66-9399.33)$ & {$[42]$} \\
\hline \multicolumn{6}{|l|}{ Productivity losses by age } \\
\hline Age group $15-24$ & $\$ 20,166.00$ & $\$ 2016.60$ & Gamma & $(\$ 16,213.54-24,118.46)$ & {$[45]$} \\
\hline Age group 25-34 & $\$ 64,686.00$ & $\$ 6468.60$ & Gamma & $(\$ 52,007.78-77,364.22)$ & {$[45]$} \\
\hline Age group $35-44$ & $\$ 87,023.00$ & $\$ 8702.30$ & Gamma & $(\$ 69,966.81-104,079.19)$ & {$[45]$} \\
\hline Age group 45-54 & $\$ 83,354.00$ & $\$ 8335.40$ & Gamma & $(\$ 67,016.92-99,691.08)$ & {$[45]$} \\
\hline Age group 55-64 & $\$ 67,990.00$ & $\$ 6799.00$ & Gamma & $(\$ 54,664.20-81,315.80)$ & {$[45]$} \\
\hline Age group $65-74$ & $\$ 38,504.00$ & $\$ 3850.40$ & Gamma & $(\$ 30,957.35-46,050.65)$ & {$[45]$} \\
\hline Age group 75-99 & $\$ 16,017.00$ & $\$ 1601.70$ & Gamma & $(\$ 12,877.73-19,156.27)$ & {$[45]$} \\
\hline
\end{tabular}


Table 2 continued

\begin{tabular}{llllll}
\hline Parameter & Base case & SE & Distribution & Lower-upper & Reference \\
\hline Drug costs & $\$ 2500$ & - & - & - & Assumption \\
\hline
\end{tabular}

The final proportion of patients by highest level of acute care in the hospital for the best supportive care (BSC) arm was calculated by adding patients who required mechanical ventilation later on in their hospital stay to the proportion requiring mechanical ventilation at baseline (admission) and by subtracting those patients from the no oxygen and oxygen without ventilation arms, respectively. The final estimate of the proportions of patients by the highest level of acute care for the BSC arm was as follows: no oxygen support, 19.29\%; oxygen support w/o mechanical ventilation, 50.76\%; mechanical ventilation, $29.95 \%$. Thus, $0.77 \%$ of patients who did not have any oxygen support at admission and $10.59 \%$ of patients who had oxygen support but no mechanical ventilation at admission were estimated to receive ventilation later during the stay in the BSC arm. According to Wortham [35] the average age of patients with COVID-19 who die during the inpatient stay is 78. Thus, we assumed that among the hospitalized patients, those that died were older (average age 78) and those that were discharged alive were younger (62.5). In absence of data on the average age of patients discharged alive, we assumed it to be equal the average age of patients admitted for COVID-19. This approach better captures the productivity losses due to premature death and provides a more conservative estimate of the productivity losses due to premature death as opposed to assuming that the average age of patients dying is the same as that of those admitted. For the distribution of highest level of acute care at admission estimates, the numbers in the SE column are sample sizes which were used in estimation of the Dirichilet distribution parameters and not absolute standard errors

$\mathrm{DRG}=$ diagnosis-related group; $\mathrm{SE}=$ standard error; $\mathrm{BSC}=$ best spportive care

clinical trials for COVID-19 treatments are stratified by the level of oxygen support received at admission (i.e., upon admission to the hospital), with varying amounts of detail regarding how patients transition to different levels of care over the course of their stay [30-33]. We used the results from the RECOVERY and WHO SOLIDARITY trials to estimate the proportion of patients who receive mechanical ventilation during their stay among those not receiving it at admission (Table 2) $[31,32]$. On the basis of results reported from the ACTT-1 trial, we determined that most patients who transition to mechanical ventilation after hospital admission (i.e., were not on mechanical ventilation at admission) were receiving some level of oxygen support at admission (93\%, Table 2). The risk ratio for the reduction in the likelihood of a patient receiving mechanical ventilation in the treatment arm was applied to the proportion of patients whose care would have deteriorated to receiving mechanical ventilation under BSC.

The average age at death among those not recovering in the hospital was based on data from the US Centers for Disease Control [35]. LOS among the patients who died was assumed to be 15 days across all care settings in both arms. Patients discharged from the hospital after receiving inpatient mechanical ventilation were assumed to have increased mortality relative to the general population at a hazard ratio of 1.33 in the first 5 years of the Markov model, based on a matched cohort study by Lone et al. comparing 5-year mortality among ICU- versus non-ICU-admitted hospital patients post-discharge (Table 1) [36].

\section{Utilities}

Health utilities were based on US age-adjusted general population utilities derived from Sullivan et al. (Table 1) [37]. For the acute care decision tree, the disutility associated with COVID-19 symptoms and additional disutility associated with each level of oxygen support were based on Padula et al., with disutilities for hospitalized patients without oxygen support, with oxygen support, and on mechanical ventilation derived from utility scores corresponding to moderate symptoms, severe symptoms, and critical care, respectively [24]. In the longterm Markov model, additional disutility was applied to patients recovering from the hospital 
after requiring mechanical ventilation in the first 5 years post-discharge. These disutilities were based on SF-36 scores from a survey by Herridge et al. that examined functional disability over 5 years in survivors of acute respiratory distress syndrome [6]. The scores were mapped to EQ-5D utilities using the algorithm defined by Ara and Brazier and shown in Table 1 [38].

\section{Cost Inputs}

All direct medical costs and the drug costs are described in Table 2. Costs for each level of care received were incorporated into the model either as bundled payments (a single reimbursement amount as per the billing diagnosisrelated group, DRG) or as FFS payments (reimbursement based on individual services rendered). Bundled payments were estimated by a weighted average of costs to commercial payers, Medicare and Medicaid [39]. A weighted approach was presented for the base case to represent a potential US payer, on average, but detailed results by payer type are also provided in the supplementary material. The weights used in the model were based on estimates obtained from payment of COVID-19 hospitalizations in the states of New York, Texas, Florida, and California, which represented the majority of COVID-19 hospitalizations nationally [39]. Medicare payments were taken from reimbursement rates released by Centers for Medicare and Medicaid Services, Medicaid payments were assumed equal to those for Medicare, and commercial payments were estimated using 2017 cost data (adjusted to 2020 USD) from the Healthcare Cost and Utilization Project (HCUP) [40]. The DRGs used to calculate the bundled payments costs for each level of oxygen support are shown in Table 2 . In the absence of data on the exact services rendered for different levels of care for COVID-19 hospitalizations, the FFS per diem costs were derived by dividing average bundled payments by average LOS for the corresponding DRGs from the HCUP data (for commercial patients) or from published phase 3 trials [30, 40, 41]. The FFS payment approach was incorporated to show the cost savings as a result of the reduction in LOS from a provider or an integrated delivery network perspective. The detailed calculations for the costs in the acute care setting for each of the payment approaches is shown in Table S6 in the supplementary material. The impact of additional or alternative reimbursement amounts was assessed by varying total payments in the one-way sensitivity analyses (OWSA, Table 2).

Drug costs for a single course of treatment were assumed to be $\$ 2500$, which approximated the cost of one bed day in our model. This was an assumption for the purposes of exploring the interplay between drug cost and outcomes. In addition, the economically justifiable price was assessed. Average annual personal healthcare spending (average across all US payers) by age was applied in the Markov model and taken from national health expenditure data provided by the Centers for Medicare and Medicaid Services [41]. Additional healthcare costs for patients discharged after receiving mechanical ventilation inpatient were applied in the first year post-discharge and based on a longitudinal study of over 800 acute respiratory distress syndrome survivors reported by Ruhl et al. (Table 2) [42].

\section{Societal Costs}

Robust published and real-world evidence estimating the impact of COVID-19 treatments on productivity are not yet available. Further, given the unprecedented state of the US economy, telework, and government support, the exact impact of an individual COVID-19 inpatient treatment on the near-term productivity of hospitalized patients is uncertain [10, 12, 43]. Therefore, to balance the importance of taking a societal perspective against the uncertainties of the current COVID-19 crisis, our model took a conservative approach to estimate the impact of productivity based only on COVID-19-related premature mortality [21]. Additional scenarios examining the impact of potential increased productivity losses due to reduced workforce participation are available in the supplementary material (Tables S7, S8) for reference. Age-based 


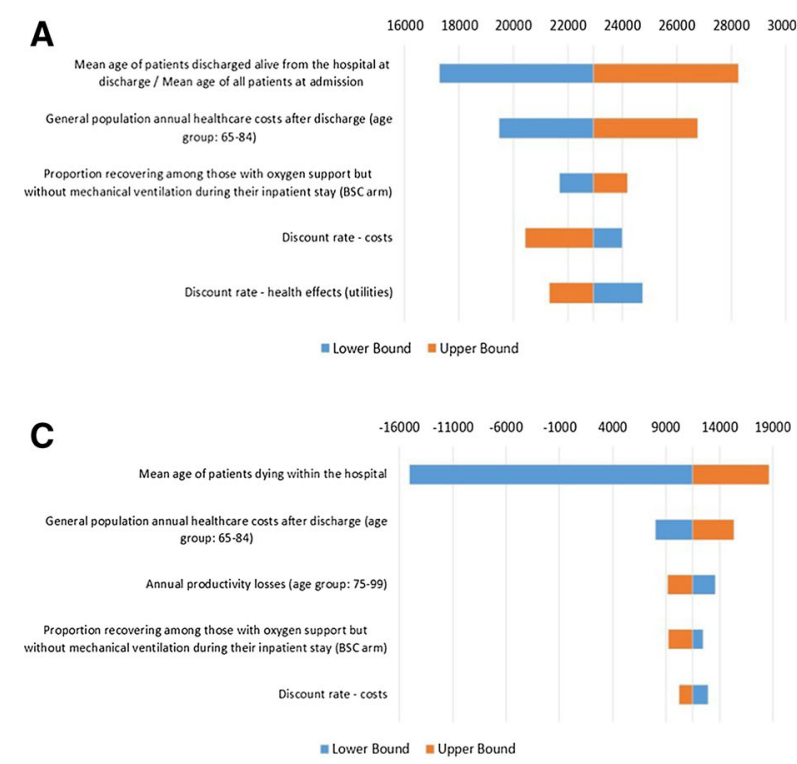

Fig. 2 Base case one-way sensitivity analyses presenting change in cost per QALY gained on the $\mathrm{x}$-axis and most influential variables on the $y$-axis. FFS = fee-for-service; ICER = incremental cost-effectiveness ratio; $\mathrm{BSC}=$ best supportive care; LOS = length of stay; OWSA = one-way sensitivity analysis. a OWSA-base case payer perspective

indirect cost estimates were taken from Grosse et al., which follows a human capital approach to estimate market productivity (e.g., wages, salaries, self-employment income, and employerpaid benefits) and non-market productivity (e.g., childcare, eldercare, household services) based on the American Community Survey, the American Time Use Survey, and the Current Population Survey [44]. Recognizing growing evidence that elderly individuals contribute to non-market productivity, the model included total productivity estimates for all age groups over 18 years [45]. Given uncertainty on growth in economic productivity and change in inflationadjusted earnings since 2016, we followed a neutral approach and used unadjusted 2016 estimates from the Grosse et al. publication [44].

\section{Model Base Case, Scenario, and Sensitivity Analyses}

For the base case, we assumed treatment reduced mortality, decreased use of mechanical ventilation, and shortened hospital LOS based on

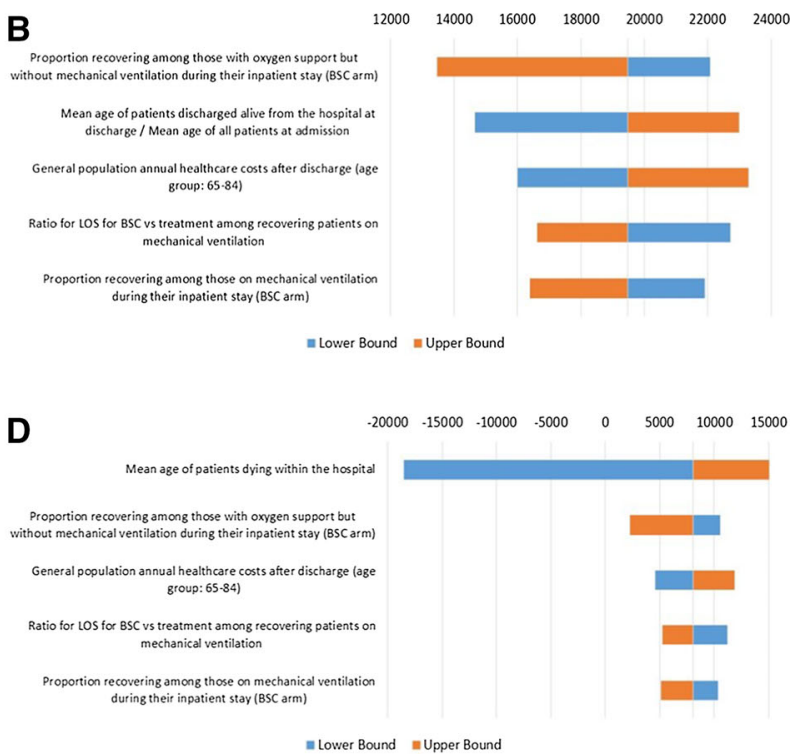

(Bundled Payment); b OWSA-base case payer perspective (FFS Payment); c OWSA-base case societal perspective (Bundled Payment); d OWSA-base case societal perspective (FFS Payment). The mean age among patients discharged alive at discharge was assumed to equal the mean age at admission among all patients admitted

plausible information from literature [31, 33]. We considered cost-effectiveness from (1) a health payer perspective, which accounted for short-term bundled payments in the hospital and long-term direct medical costs, (2) a societal perspective, which included productivity losses due to premature COVID-19-related mortality, and (3) a FFS approach, which included drug costs and per diem hospital payments instead of bundled costs. Scenario analyses were conducted to understand the impact of different treatment profiles by removing the LOS and reduced mechanical ventilation benefits. We tested the impact of parameter uncertainty through univariate and probabilistic sensitivity analyses.

\section{RESULTS}

\section{Base Case}

The base case analyses describe the cost-effectiveness of treating hospitalized patients with COVID-19 from various perspectives within the 


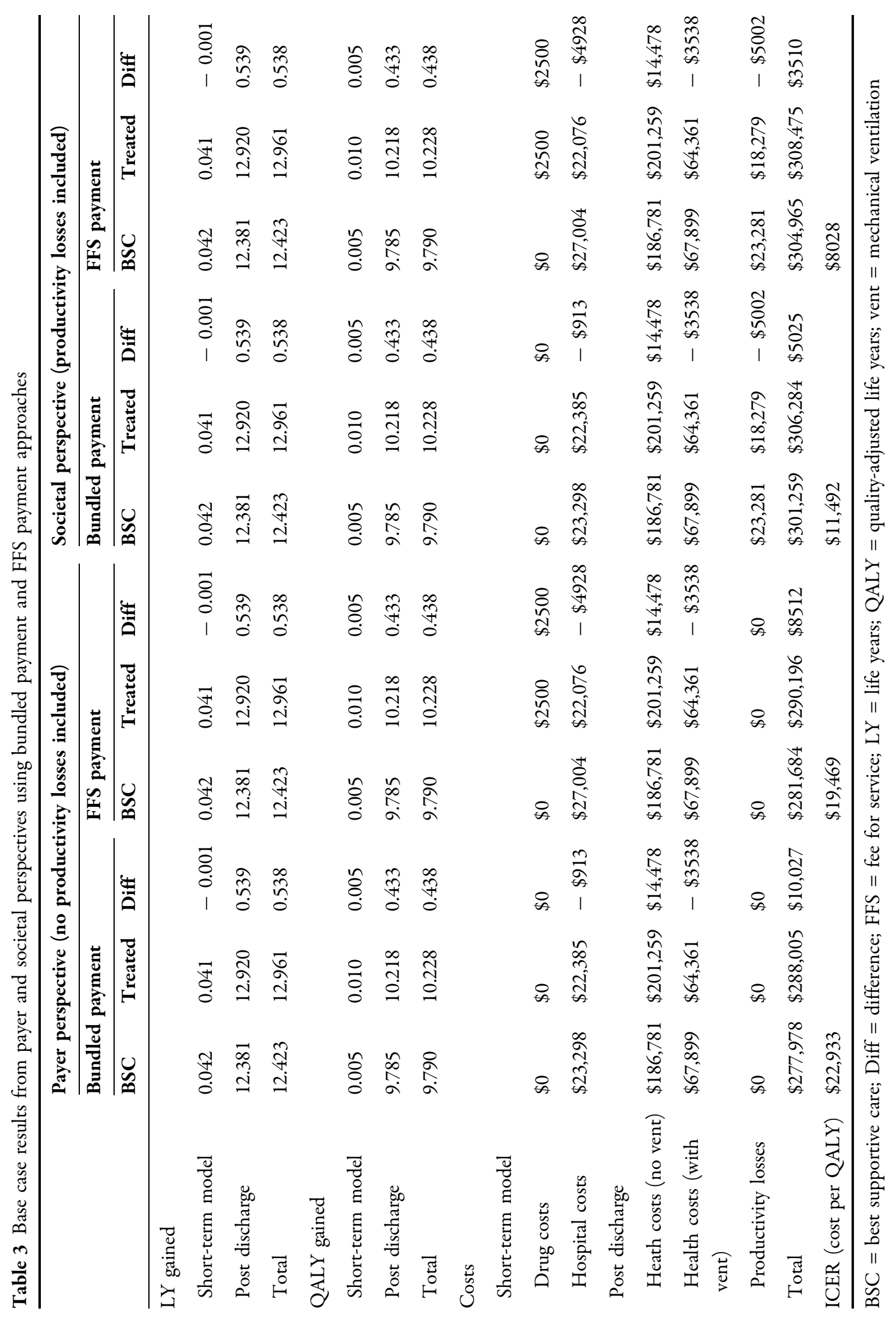


US healthcare system. From all perspectives shown in Table 3 , treatment in the hospital results in a 0.538 total life year gain and 0.438 QALY gain over a patient's lifetime, while $\$ 14,478$ in additional long-term health costs are incurred due to the survivor's paradox against \$3538 in long-term savings from fewer patients discharged after receiving mechanical ventilation. From the health payer perspective, an additional $\$ 913$ is offset in the hospital due to shifts in bundled payments from decreased use of mechanical ventilation, resulting in a cost per QALY gained of $\$ 22,933$. From the societal perspective, another $\$ 5002$ in productivity losses are avoided from decreased inpatient mortality, reducing the cost per QALY gained to $\$ 11,492$. For the FFS approach, the assumed drug cost of $\$ 2500$ is offset by an estimated $\$ 4928$ in hospital per diem savings, given an average LOS reduction of 2.7 days. This leads to a cost per QALY gained of $\$ 19,469$, which is lowered to $\$ 8028$ when including societal impacts. Doubling and tripling the drug costs to $\$ 5000$ and $\$ 7500$ increases the cost per QALY gained to $\$ 25,187$ and $\$ 30,905$, respectively. For the FFS scenario where cost of the intervention is relevant in assessing the cost per QALY gained, value-based prices for a potential treatment with the base case clinical profile are $\$ 37,710$ and $\$ 59,572$ at the $\$ 100 \mathrm{~K}$ and $\$ 150 \mathrm{~K}$ willingness-to-pay (WTP) thresholds, respectively. Comparing results from the acute portion of the model to the lifetime Markov, we can see that results evolve from cost saving during the inpatient stay to cost-effective over a patient's lifetime given the survivor's paradox.

OWSAs revealed that the most influential parameters differed by the perspective of the stakeholder (Fig. 2). From the health payer perspective, the average age of hospitalized patients had the largest effect, with an age range of 50-75 yielding cost per QALY gained estimates between $\$ 17,287$ and $\$ 28,269$. From the societal perspective, the average age of patients who died during their inpatient stay was the most influential variable, since age at death influences the degree to which productivity losses could have been avoided by surviving the hospital stay. For example, assuming that the average age at death in the hospital is as high as
95 yields a cost per QALY gained of $\$ 18,632$, while assuming an average age at death as low as 64 yields overall cost-saving scenarios due to additional productivity losses avoided at the lower age range. Finally, from the FFS perspective, the most influential variable is the proportion recovering among patients receiving oxygen support but not mechanical ventilation in the hospital, with upper bound costs per QALY gained of $\$ 22,074$ when the likelihood of recovery is reduced to $64 \%$. All univariate sensitivity analyses produced upper bound cost per QALY estimates well below commonly accepted WTP thresholds. Additional parameters among the most influential throughout all the scenarios explored included general population healthcare costs for patients 65 and older, discount rates for costs and efficacy, the proportion recovering among patients receiving mechanical ventilation, and the reduction in patients receiving mechanical ventilation under BSC. Tornado diagrams for all OWSA runs are available in the supplementary material (Fig. S1, S2).

\section{Scenario Analyses}

Two alternative clinical profiles were tested to understand how unique clinical benefits translated into different cost-effectiveness outcomes (Table 4). First, removing the LOS benefit (and assuming only treatment effects on mortality and reduced use of mechanical ventilation) led to marginal increases in the cost per QALY gained from the health payer perspective with $(\$ 11,492$ to $\$ 11,615)$ and without $(\$ 22,933$ to $\$ 23,178$ ) societal impacts, whereas the cost per QALY gained from the FFS perspective increased by about 10,000 dollars $(\$ 19,469$ to $\$ 29,108)$. This increase is due to LOS having no impact on inpatient costs to a health payer reimbursing via bundled payments, whereas under the FFS model the drug cost was no longer offset by reduced per diem hospital payments. Removing both LOS and reduced use of mechanical ventilation from the treatment profile (and assuming only a mortality benefit) produced results similar to removing LOS alone, with only marginal increases in cost per QALY gained across 


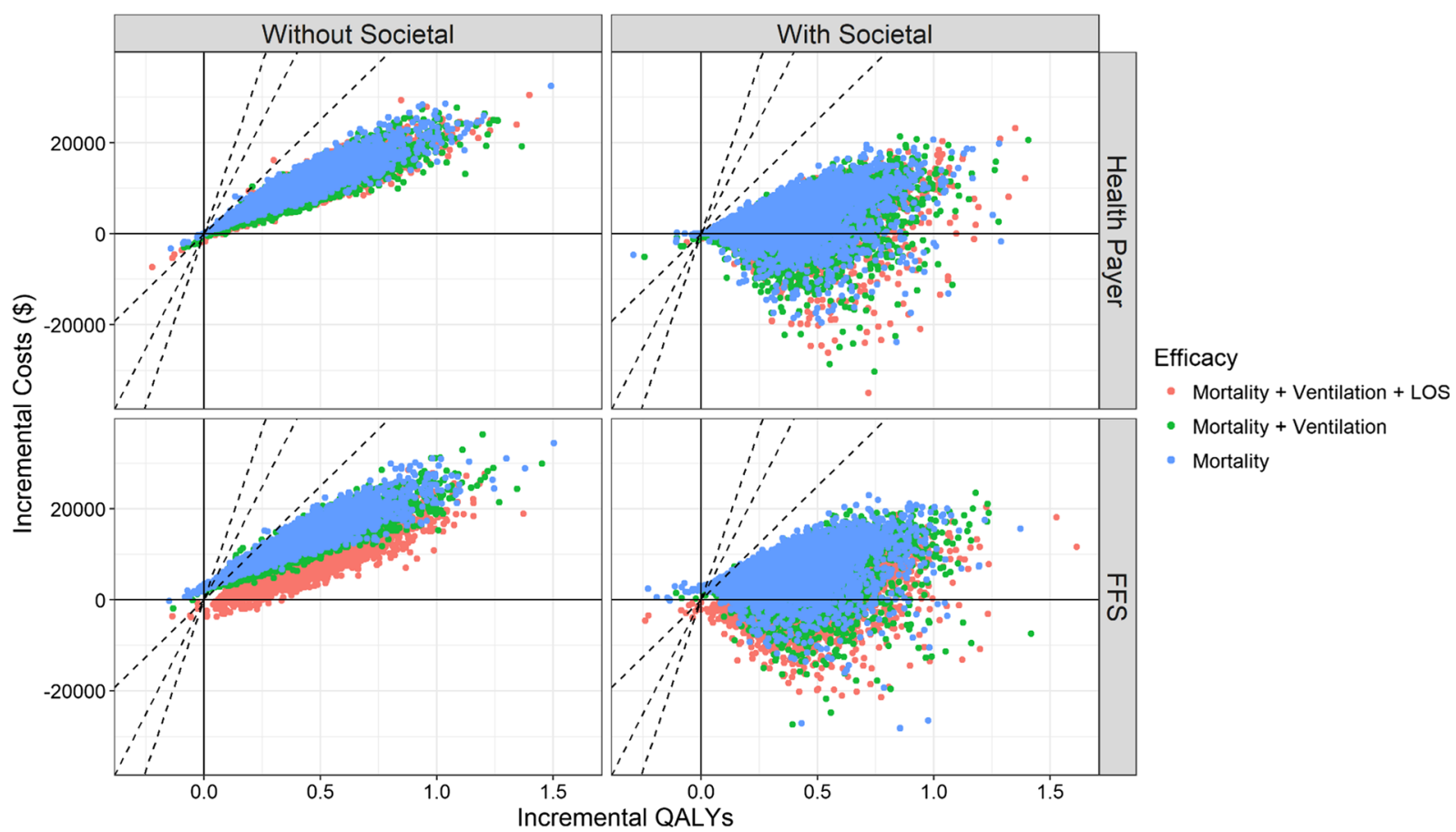

Fig. 3 Base case probabilistic sensitivity analysis. Dashed lines represent willingness to pay thresholds at $\$ 150 \mathrm{~K}$ (top), $\$ 100 \mathrm{~K}$ (middle), and $\$ 50 \mathrm{~K}$ (bottom) per QALY, respectively. Per the legend to the right of the figure, the

all perspectives. The marginal increases were due to differences in the long-term effects of mechanical ventilation on mortality, quality of life, and healthcare costs being mostly cancelled out by the mortality benefit of treatment, which results in a similar proportion of patients being discharged from the hospital after mechanical ventilation as in BSC (Fig. S3 in the supplementary material).

Trends in the OWSAs were generally similar when examining the alternative clinical scenarios where treatment offers only a mortality benefit or only a mortality benefit and reduced use of mechanical ventilation (Figs. S1, S2; Tables S2, S3 in the supplementary material). Viewing findings from all OWSA runs in aggregate across perspectives and clinical profiles explored, we see that in addition to the expected clinical variables, healthcare and productivity costs, patient age at recovery, and patient age at death are important model parameters (Table S4 in the supplementary material). base case and scenario clinical profiles are all plotted to show the overlap of outcomes given changes in efficacy elements

\section{Probabilistic Sensitivity Analyses}

Probabilistic sensitivity analyses (PSA) were run across all perspectives for the model base case as well as the two alternative clinical scenarios in order to understand the robustness of model conclusions and to identify any notable differences when clinical assumptions changed. The PSA were run with 5000 draws to produce stable results. For the base case clinical profile, upper bounds of $95 \%$ credible intervals ranged from $\$ 18,636$ (FFS, including societal impacts) to $\$ 30,937$ (health payer, without societal impacts). Over $99 \%$ of draws had a cost per QALY gained below the $\$ 100,000$ and $\$ 150,000$ WTP thresholds across all clinical profiles and all perspectives. Without including societal impacts, all draws resulted in the treatment of interest being more costly and more effective, with the exception of the base case treatment profile (which includes the LOS benefit), in which $1.4 \%$ of draws were cost-saving under the 
Table 4 Incremental cost-effectiveness ratios by treatment profiles

\begin{tabular}{|c|c|c|c|c|c|}
\hline Perspective & $\begin{array}{l}\text { Payment } \\
\text { approach }\end{array}$ & Treatment profiles ${ }^{a}$ & ICER & $\begin{array}{l}\text { Relative } \\
\text { change from } \\
\text { base case }(\%)\end{array}$ & Key drivers for change from base case \\
\hline \multirow[t]{6}{*}{ Payer } & \multirow[t]{3}{*}{ Bundled } & Base case & $\$ 22,933$ & - & - \\
\hline & & Mortality + ventilation & $\$ 23,178$ & 1 & $\begin{array}{l}\text { Fewer QALYs gained in hospital slightly } \\
\text { increases ICER }\end{array}$ \\
\hline & & Mortality & $\$ 25,985$ & 13 & $\begin{array}{l}\text { Fewer QALYs gained in hospital and no } \\
\text { more savings in bundled payments }\end{array}$ \\
\hline & \multirow[t]{3}{*}{ FFS } & Base case & $\$ 19,469$ & - & - \\
\hline & & Mortality + ventilation & $\$ 29,108$ & 50 & $\begin{array}{l}\text { Per diem hospital costs no longer offset the } \\
\text { cost of the drug }\end{array}$ \\
\hline & & Mortality & $\$ 32,864$ & 69 & $\begin{array}{l}\text { Per diem hospital costs no longer offset the } \\
\text { cost of the drug and no more savings in } \\
\text { bundled payments }\end{array}$ \\
\hline \multirow[t]{6}{*}{ Societal } & \multirow[t]{3}{*}{ Bundled } & Base case & $\$ 11,492$ & - & - \\
\hline & & Mortality + ventilation & $\$ 11,615$ & 1 & $\begin{array}{l}\text { Fewer QALYs gained in hospital slightly } \\
\text { increases ICER }\end{array}$ \\
\hline & & Mortality & $\$ 14,143$ & 23 & $\begin{array}{l}\text { Fewer QALYs gained in hospital and no } \\
\text { more savings in bundled payments }\end{array}$ \\
\hline & \multirow[t]{3}{*}{ FFS } & Base case & $\$ 8028$ & - & - \\
\hline & & Mortality + ventilation & $\$ 17,545$ & 119 & $\begin{array}{l}\text { Per diem hospital costs no longer offset the } \\
\text { cost of the drug }\end{array}$ \\
\hline & & Mortality & $\$ 21,022$ & 162 & $\begin{array}{l}\text { Per diem hospital costs no longer offset the } \\
\text { cost of the drug and no more savings in } \\
\text { bundled payments }\end{array}$ \\
\hline
\end{tabular}

\footnotetext{
${ }^{a}$ The base case treatment profile considers the potential treatment reduces mortality, the use of mechanical ventilation, and hospital length of stay; mortality and ventilation profile considers the potential treatment reduces mortality and the use of mechanical ventilation; mortality profile considers the potential treatment reduces mortality only and has no impact on use of mechanical ventilation or hospital length of stay

FFS = fee for service; ICER = incremental cost-effectiveness ratio; QALYs = quality-adjusted life years
}

FFS perspective (Fig. 3). When including societal impacts, draws for all three treatment profiles were similarly clustered in the northeast and southeast quadrants, with $18.4 \%$ and $15.6 \%$ of draws resulting in cost-saving scenarios for health payer and FFS perspectives, respectively (Fig. 3).

\section{DISCUSSION}

To the authors' knowledge, this study is the first published cost-effectiveness evaluation of treatments for hospitalized COVID-19 from both a US health payer and societal perspective. By modeling the impact of potential clinical profiles in a cost-effectiveness framework for acute COVID-19 treatments, we both establish how application of recommended modeling 
best practices impacts assessment of cost per QALY gained outcomes and, on the basis of the current model structure and available clinical evidence, identify the most influential variables impacting costs and health effects to inform future evidence gathering. Viewing results in aggregate, we find that potential treatments reducing LOS, COVID-19-related mortality, and incidence of mechanical ventilation are likely to be cost-effective, as all deterministic and sensitivity analyses resulted in the cost per QALY gained falling far below WTP thresholds from US health payer, societal, and FFS perspectives.

Examining trends in the results across additional potential clinical profiles, we see that treatments conferring reduced hospital LOS demonstrate an important cost interplay to consider for payers that operate under a FFS reimbursement system or for hospital providers. With inclusion of post-discharge morbidity and societal impacts, we see that even small treatment-related changes during the acute stay can lead to notable shifts in QALYs and costs over a patient's lifetime. Further, important consideration should be given to the assumed age of patients that are hospitalized for COVID-19 as well as average age at death in the hospital, since these are among the most influential factors in determining cost-effectiveness through either the survivor's paradox or potential productivity losses from the societal perspective. While we found no available peer-reviewed COVID-19 economic modeling publications specifically examining the cost-effectiveness of inpatient treatments, the findings of our work are consistent with conclusions of a recent review article examining cost-effectiveness of antiviral treatments for the H1N1 pandemic [46]. Although the recent review article by Dawoud and Soliman based their findings on simulation models and did not specifically focus on cost-effectiveness of inpatient treatments, both studies reached similar conclusions of likely cost-effective treatments and the importance of considering pandemic severity and disease characteristics on model outcomes.

To the extent possible, this study follows the recommendations of the Second Panel on CostEffectiveness in Health and Medicine by evaluating cost-effectiveness from both a health payer and societal perspective [21]. While robust data on COVID-related productivity (e.g., absenteeism, presenteeism, household contributions, and caregiving) in surviving patients and COVID-related impact on other non-healthcare sector (e.g., consumption, social services) elements are not yet available, anchoring productivity losses to mortality allows for a conservative estimate to inform current decision-making following recommended best practices $[21,22]$. As more data on treatment performance and COVID-19 burden emerge, models will need to evolve accordingly. This may take the form of updated inputs or modifications to the model structure to capture important inpatient nuance (e.g., bundled payment implications of improving ordinal scale ratings during an inpatient stay) and downstream effects beyond ventilation morbidity. Even with conservative assumptions on societal impact, we find that our limited societal perspective consistently produced cost per QALY gained estimates that were at least $40 \%$ lower than those for the health payer perspective.

Our analysis also expands beyond existing models by seeking to better reflect the longterm burden of COVID-19 and the costs to various stakeholders. Specifically, the Institute for Clinical and Economic Review published several reports on their CEA of remdesivir for the treatment COVID-19, which employs a similar underlying structure and generally similar model parameters $[15,23]$. Despite published best practice recommendations and suggestions from the US health economics and outcomes research community, their model did not attempt to quantify the societal impact of COVID-19 treatment [12, 47]. Further, their model fails to capture an important aspect of the downstream effects of COVID-19 treatments by not incorporating post-ventilation morbidity and mortality. Lastly, their model mixes cost elements from several perspectives in the health system base case by including both costs faced by the typical US third-party payer (i.e., bundled payments) and by provider stakeholders (i.e., inpatient COVID-19 drug costs). In total, these structural and perspective design elements 
lead to an overestimation of incremental costs and an underestimation of incremental health effects and productivity gains, ultimately undervaluing inpatient COVID-19 treatments.

As with any modeling exercise, there are several limitations of this study that should be noted when interpreting findings. First, as data on the COVID-19 pandemic is changing daily but still immature by real-world evidence standards, our model is based on evidence available today and may therefore oversimplify the COVID-19 patient journey and long-term burden. While we sought to use best available information to begin to capture the long-term morbidity and mortality following a COVID-19 hospitalization, we expect that the model structure will need to evolve to be more complex as more data emerges. Next, given the study objective to model the cost-effectiveness of individual potential treatments, our analysis does not explicitly examine the impact of emerging inpatient treatments that may be used in combination to potentially confer additional clinical benefits. At present, the treatment landscape for COVID-19 is evolving at an unprecedented pace with over 1400 active clinical trials [11]. Through the scenario analyses, we found any effective treatments with similar clinical and cost profiles are likely to be cost-effective. Next, uncertainty remains about the long-term outcomes for COVID-19 survivors. Given the lack of robust real-world and long-term trial or observational data on patients with COVID-19 who received mechanical ventilation, our analysis leveraged long-term data from patients with acute respiratory distress syndrome (ARDS). While COVID-19-associated ARDS has similar respiratory system mechanics to historical ARDS, there is still limited data on the duration of mechanical ventilation and the long-term impacts of ventilation in patients with COVID-19 that may differ from historical ARDS [48, 49]. However, we took a conservative approach by assuming that patients discharged without having received inpatient ventilation would have mortality similar to the general population, those discharged after receiving mechanical ventilation would have increased mortality similar to patients coming out of the ICU, and that increased mortality relative to the general population would last for only 5 years post-discharge.

Similarly, a high level of uncertainty exists for many model parameters, including but not limited to exact reimbursement values for bundled care, the impact of provider-level practice patterns on LOS and other key hospital outcomes, and change in total market and nonmarket productivity over time. We sought to explore the impact of these elements through extensive scenario and sensitivity analysis, finding that results were robust and consistent. Finally, as this study provides a cost-effectiveness framework based on potential treatments, our proxy assumption of a drug cost equal to one inpatient day may not reflect final pricing of future products. As the majority of US payers operate under bundled payment systems for inpatient care, model results for the payer and societal perspective are not sensitive to the cost of inpatient COVID-19 treatments. However, doubling and tripling the assumed drug cost still yields cost-effective scenarios from the FFS perspective, and existing COVID-19 treatments, including dexamethasone and remdesivir, are similar or less than this proxy amount.

Furthermore, our model takes a societal perspective based solely on COVID-19-related mortality, with scenarios examining the impact of additional productivity losses for patients post-ventilation. This estimation likely undervalues the true societal impact of COVID-19 treatments and highlights the need for more data gathering on COVID-19-related impact through future clinical trials, post hoc studies, and real-world data. Nonetheless, we demonstrate that the societal benefits of a treatment for COVID-19 can be quantified and the societal benefit greatly influences the cost per QALY. Further, our OWSAs demonstrate that from a societal perspective, age at death is by far the most influential factor in determining the cost per QALY gained. This suggests that future evidence regarding the age of COVID-19 patients for whom premature death can be avoided could play a large role in reducing the uncertainty around potential productivity losses avoided through life-saving treatments.

This study establishes important foundational information on the predicted cost- 
effectiveness of available and in-development inpatient treatments for COVID-19. However, it also highlights important areas for future research. As more data becomes available, future updates to this cost-effectiveness framework can explore how combinations and sequences of treatments across potential subpopulations (e.g., no oxygen supplementation, patients in ICU) impact downstream costs and effects. Future studies could also build on our univariate exploration of important parameters to conduct a formal value of information analysis to aid in prioritizing evidence generation. Furthermore, congruent with the ongoing discussions around COVID-19 value, we recognize that treatments in a pandemic may confer additional benefits beyond those captured in conventional CEA, including value of hope, insurance value, and the impact of treatments on health inequality [50-52]. The research community has advanced the methods to estimate these additional value elements under a cost-effectiveness framework. Future research on the value of COVID-19 treatments could seek to quantify the impact of these additional value elements on CEA output. Given the observed impact of COVID-19 on disadvantaged populations, further research could also consider how treatments impact health equity and underlying health disparities [50, 53, 54].

\section{CONCLUSION}

The COVID-19 pandemic has drastically affected individual and population health as well as the global economy. While many vaccines and treatments are in development, there is a need for a common cost-effectiveness framework to assess the value of COVID-19 treatments when they become available. Effective COVID-19 treatments for hospitalized patients may not only reduce disease burden but also represent good value for the health system. We also demonstrate that, despite limited data available on the long-term impact of invasive mechanical ventilation and productivity of COVID-19 patients post-discharge, it is possible to estimate the cost-effectiveness of inpatient treatments for COVID-19 from a societal perspective using a conservative approach to help guide future decisions on allocation of healthcare resources.

\section{ACKNOWLEDGEMENTS}

Funding. This study was funded by Genentech, Inc., a member of the Roche Group. Genentech, Inc also provided funding for the journal's Rapid Service and Open Access Fee.

Authorship. All named authors meet the International Committee of Medical Journal Editors (ICMJE) criteria for authorship for this article, take responsibility for the integrity of the work as a whole, and have given their approval for this version to be published.

Disclosures. Yang Meng and David Elsea are employees of BresMed Health Solutions and supported model development through a consulting contract with Genentech, Inc. Stacey Kowal, Daniel Sheinson, Joseph Dang and Anuj Shah are employees and stockholders of Genentech.

Compliance with Ethics Guidelines. This article does not contain any new studies with human or animal subjects performed by any of the authors.

Data Availability. Qualified researchers may request access to individual patient level data through the clinical study data request platform

(https://www. clinicalstudydatarequest.com). Further details on Roche's criteria for eligible studies are available here (https://clinicalstudydatarequest.com/ Study-Sponsors/Study-Sponsors-Roche.aspx).

For further details on Roche's Global Policy on the Sharing of Clinical Information and how to request access to related clinical study documents, see here (https://www.roche.com/ research_and_development/who_we_are_how_ we_work/clinical_trials/our_commitment_to_ data_sharing.htm).

Open Access. This article is licensed under a Creative Commons Attribution- 
NonCommercial 4.0 International License, which permits any non-commercial use, sharing, adaptation, distribution and reproduction in any medium or format, as long as you give appropriate credit to the original author(s) and the source, provide a link to the Creative Commons licence, and indicate if changes were made. The images or other third party material in this article are included in the article's Creative Commons licence, unless indicated otherwise in a credit line to the material. If material is not included in the article's Creative Commons licence and your intended use is not permitted by statutory regulation or exceeds the permitted use, you will need to obtain permission directly from the copyright holder. To view a copy of this licence, visit http:// creativecommons.org/licenses/by-nc/4.0/.

\section{REFERENCES}

1. Johns Hopkins University. Mortality analyses. 2020. https://coronavirus.jhu.edu/data/mortality. Accessed 3 Nov 2020.

2. Centers for Disease Control and Prevention. COVIDView: a weekly surveillance summary of US COVID-19 activity. 2020. https://www.cdc.gov/ coronavirus/2019-ncov/covid-data/covidview/ index.html. Accessed 21 July 2020.

3. Khera R, Jain S, Lin Z, Ross JS, Krumholz H. Evaluation of the anticipated burden of COVID-19 on hospital-based healthcare services across the United States. MedRxiv. 2020. https://www.medrxiv.org/ content/medrxiv/early/2020/04/03/2020.04.01. 20050492.full.pdf.

4. Kim L, Garg S, O'Halloran A, Factors R, et al. Risk factors for intensive care unit admission and inhospital mortality among hospitalized adults identified through the U.S. Coronavirus Disease 2019 (COVID-19)-Associated Hospitalization Surveillance Network (COVID-NET). Clin Infect Dis. 2020. https://doi.org/10.1093/cid/ciaa1012.

5. Hornig M, Tuller D. Why do some recover from COVID-19 quickly, while others seem likely to face long-term disability? 2020. https://www. healthaffairs.org/do/10.1377/hblog20200603.

471204/full/. Accessed June 82020.

6. Herridge MS, Tansey CM, Matté A, et al. Functional disability 5 years after acute respiratory distress syndrome. N Engl J Med 2011;364(14):1293-1304. https://pubmed.ncbi.nlm.nih.gov/21470008/.

7. The World Bank. COVID-19 to plunge global economy into worst recession since World War II. 2020. https://www.worldbank.org/en/news/pressrelease/2020/06/08/covid-19-to-plunge-globaleconomy-into-worst-recession-since-world-war-ii. Accessed 8 June 2020.

8. Congressional Budget Office. Comparison of CBO's May 2020 interim projections of gross domestic product and its January 2020 baseline projections. 2020. https://www.cbo.gov/publication/56376. Accessed 1 June 2020.

9. United States Department of Labor. Office of unemployment insurance: unemployment insurance weekly claims. 2020. https://oui.doleta.gov/ unemploy/claims_arch.asp. Accessed 3 Nov 2020.

10. Congressional Budget Office. Budgetary effects of the 2020 coronavirus pandemic. 2020. https:// www.cbo.gov/publication/56388. Accessed 5 June 2020.

11. PhRMA. COVID-19 treatment progress. 2020. https://phrma.org/Coronavirus/Activity-Tracker. Accessed 3 Sept 2020.

12. Cohen JT, Neumann PJ, Ollendorf DA. Valuing and pricing remdesivir: should drug makers get paid for helping us get back to work? 2020. https://www. healthaffairs.org/do/10.1377/hblog20200518. 966027/full/. Accessed 21 July 2020.

13. Dubois RW. It's time to talk about COVID-19 prices. 2020. https://www.healthaffairs.org/do/10.1377/ hblog20200518.302353/full/. Accessed 21 July 2020.

14. Kamal-Bahl S, Willkek R, Puckett JT, Doshi JA. The case for using novel value elements when assessing COVID-19 vaccines and therapeutics. 2020. https:// www.healthaffairs.org/do/10.1377/hblog20200616. 451000/full/. Accessed 21 July 2020.

15. Institute for Clinical and Economic Review. Alternative pricing models for remdesivir and other potential treatments for COVID-19: second assessment updated. 2020. https://icer.org/explore-ourresearch/policy-papers/covid-19/. Accessed 10 Nov 2020.

16. National Institutes of Health. COVID-19 treatment guidelines. 2020 . https://www. covid19treatmentguidelines.nih.gov/. Accessed 3 Sept 2020.

17. U.S. Food and Drug Administration. FDA issues emergency use authorization for convalescent plasma as potential promising COVID-19 
treatment, another achievement in administration's fight against pandemic. 2020. https://www. fda.gov/news-events/press-announcements/fdaissues-emergency-use-authorization-convalescentplasma-potential-promising-covid-19-treatment. Accessed 23 Aug 2020.

18. U.S. Food and Drug Administration. COVID-19 update: FDA broadens emergency use authorization for Veklury (remdesivir) to include all hospitalized patients for treatment of COVID-19. 2020. https:// www.fda.gov/news-events/press-announcements/ covid-19-update-fda-broadens-emergency-useauthorization-veklury-remdesivir-include-allhospitalized. Accessed 28 Aug 2020.

19. Covid-nma. Living mapping and living systematic review of Covid-19 studies. 2020. https://covidnma.com/. Accessed 19 Aug 2020.

20. Siemieniuk RA, Bartoszko JJ, Ge L, et al. Drug treatments for covid-19: living systematic review and network meta-analysis. BMJ. 2020;370:m2980. https://www.bmj.com/content/bmj/370/bmj. m2980.full.pdf.

21. Sanders GD, Neumann PJ, Basu A, et al. Recommendations for conduct, methodological practices, and reporting of cost-effectiveness analyses: second panel on cost-effectiveness in health and medicine. JAMA. 2016;316(10):1093-1103. https://pubmed. ncbi.nlm.nih.gov/27623463/.

22. Kim DD, Silver MC, Kunst N, Cohen JT, Ollendorf DA, Neumann PJ. Perspective and costing in costeffectiveness analysis, 1974-2018. PharmacoEconomics. 2020. https://doi.org/10.1007/s40273-02000942-2.

23. Institute for Clinical and Economic Review. Alternative pricing models for remdesivir and other potential treatments for COVID-19: preliminary assessment. 2020. https://icer.org/wp-content/ uploads/2020/10/ICER-COVID_Initial_Abstract_ 05012020.pdf. Accessed 1 May 2020.

24. Padula WV, Malaviya S, Reid NM, Tierce J, Alexander GC. Economic value of treatment and vaccine to address the COVID-19 pandemic: a U.S. cost-effectiveness and budget impact analysis. SSRN. 2020.

25. Ramsey S, Willke R, Briggs A, et al. Good research practices for cost-effectiveness analysis alongside clinical trials: the ISPOR RCT-CEA task force report. Value Health. 2005;8(5):521-533. https://www. ncbi.nlm.nih.gov/pubmed/16176491.

26. Garrison LP, Jr., Neumann PJ, Willke RJ, et al. A health economics approach to US value assessment frameworks-summary and recommendations of the ISPOR special task force report [7]. Value Health.
2018;21(2):161-165. https://www.ncbi.nlm.nih. gov/pubmed/29477394.

27. Eddy DM, Hollingworth W, Caro JJ, et al. Model transparency and validation: a report of the ISPORSMDM Modeling Good Research Practices Task Force-7. Med Decis Mak. 2012;32(5):733-743. https://www.ncbi.nlm.nih.gov/pubmed/22990088.

28. Stijntje D, Krijkamp E, Kunst N, Hunink M. Use of remdesivir for COVID-19: forgone benefit due to delayed implementation outweighs the value of doing more trials. In: Society for Medical Decision Making: 42nd Annual Meeting. 2020.

29. U.S. Bureau of Labor Statistics. Consumer price index. 2020. https://www.bls.gov/cpi/factsheets/. Accessed 3 Sept 2020.

30. Beigel JH, Tomashek KM, Dodd LE, et al. Remdesivir for the treatment of Covid-19 - preliminary report. N Engl J Med. 2020. https://www.nejm.org/doi/full/ 10.1056/NEJMoa2007764.

31. The RECOVERY Collaborative Group. Dexamethasone in hospitalized patients with Covid-19 preliminary report. N Engl J Med. 2020. https:// www.nejm.org/doi/full/10.1056/NEJMoa2021436.

32. World Health Organization Solidarity Trial Consortium. Repurposed antiviral drugs for COVID-19 interim WHO SOLIDARITY Trial results. MedRxiv. 2020. https://www.medrxiv.org/content/10.1101/ 2020.10.15.20209817v1.

33. Beigel JH, Tomashek KM, Dodd LE, et al. Remdesivir for the treatment of Covid-19 - final report. N Engl J Med. 2020. https://www.ncbi.nlm.nih.gov/ pubmed/32445440.

34. United States Social Security Administration. 2017 Actuarial life table. https://www.ssa.gov/oact/ STATS/table4c6.html. Accessed 22 July 2020.

35. Wortham JM. Characteristics of persons who died with COVID-19-United States, February 12-May 18, 2020. MMWR. Morb Mortal Wkly Re. 2020;69.

36. Lone NI, Gillies MA, Haddow C, et al. Five-year mortality and hospital costs associated with surviving intensive care. Am J Respir Crit Care Med. 2016;194(2):198-208. https://pubmed.ncbi.nlm. nih.gov/26815887/.

37. Sullivan PW, Ghushchyan V. Preference-based EQ$5 \mathrm{D}$ index scores for chronic conditions in the United States. Med Decis Mak. 2006;26(4):410-420. https://pubmed.ncbi.nlm.nih.gov/16855129/.

38. Ara R, Brazier J. Deriving an algorithm to convert the eight mean SF-36 dimension scores into a mean EQ-5D preference-based score from published 
studies (where patient level data are not available). Value Health. 2008;11(7):1131-1143. https:// pubmed.ncbi.nlm.nih.gov/18489495/.

39. Glied S ZB, Chakraborty O, and Tang A. Who will pay for COVID-19 hospital care: looking at payers across states. 2020.2 https://www. commonwealthfund.org/blog/2020/who-will-paycovid-19-hospital-care-looking-payers-across-states. Accessed 9 Nov 2020.

40. Centers for Medicare and Medicaid Services. COVID-19 frequently asked questions (FAQs) on medicare fee-for-service (FFS) billing. 2020. https:// www.cms.gov/files/document/03092020-covid-19faqs-508.pdf. Accessed 22 July 2020.

41. Centers for Medicare and Medicaid Services. Health expenditures by age and gender. 2019. https:// www.cms.gov/Research-Statistics-Data-andSystems/Statistics-Trends-and-Reports/ NationalHealthExpendData/Age-and-Gender. Accessed 22 July 2020.

42. Ruhl AP, Huang M, Colantuoni E, et al. Healthcare utilization and costs in ARDS survivors: a 1-year longitudinal national US multicenter study. Intensive Care Med. 2017;43(7):980-991. https:// pubmed.ncbi.nlm.nih.gov/28550403/.

43. Brynjolfsson E, Horton JJ, Ozimek A, Rock D, Sharma G, TuYe H-Y. Covid-19 and remote work: an early look at US data. Natl Bureau Econ Res. 2020;0898-2937.

44. Grosse SD, Krueger KV, Pike J. Estimated annual and lifetime labor productivity in the United States, 2016: implications for economic evaluations. J Med Econ. 2019;22(6):501-508. https://pubmed.ncbi. nlm.nih.gov/30384792.

45. Grosse SD, Krueger KV, Mvundura M. Economic productivity by age and sex: 2007 estimates for the United States. Med Care. 2009;47(7 Suppl 1): S94-S103. $19536021 /$.

46. Dawoud DM, Soliman KY. Cost-effectiveness of antiviral treatments for pandemics and outbreaks of respiratory illnesses, including COVID-19: a systematic review of published economic evaluations. Value Health. 2020;23(11):1409-1422. https:// www.ncbi.nlm.nih.gov/pubmed/33127010.

47. Garthwaite C. Beware of underpriced drugs for COVID-19 treatments. Washington Post. May 18, 2020.

48. Fan E, Beitler JR, Brochard L, et al. COVID-19-associated acute respiratory distress syndrome: is a different approach to management warranted? Lancet Respir Med. 2020. https://doi.org/10.1016/ S2213-2600(20)30304-0.

49. Almeshari MA, Alobaidi NY, Al Asmri M, et al. Mechanical ventilation utilization in COVID-19: a systematic review and meta-analysis. MedRxiv. 2020. 20122069.

50. Asaria M, Griffin S, Cookson R, Whyte S, Tappenden P. Distributional cost-effectiveness analysis of health care programmes-a methodological case study of the UK Bowel Cancer Screening Programme. Health Econ. 2015;24(6):742-754. https:// pubmed.ncbi.nlm.nih.gov/24798212/.

51. Lakdawalla DN, Doshi JA, Garrison LP Jr, Phelps CE, Basu A, Danzon PM. Defining elements of value in health care-a health economics approach: an ISPOR Special Task Force Report [3]. Value Health. 2018;21(2):131-139. https://pubmed.ncbi.nlm.nih. gov/29477390/.

52. Lakdawalla DN, Phelps CE. Evaluation of medical technologies with uncertain benefits. Natl Bureau Econ Res. 2019;0898-2937.

53. Shafrin J, Venkatachalam M. Creating incentives to narrow the gap in health outcomes: expanding value assessment to incorporate health inequality. 2020. https://www.healthaffairs.org/do/10.1377/ hblog20200708.876257/full/. Accessed 12 Aug 2020.

54. Kaiser Family Foundation. Racial disparities in COVID-19: key findings from available data and analysis. 2020. https://www.kff.org/disparitiespolicy/issue-brief/racial-disparities-covid-19-keyfindings-available-data-analysis/?utm_campaign= KFF-2020-The-Latest\&utm_medium=email\&_ hsmi $=93555646 \& \_$hsenc $=$p2ANqtz92fyJ7oGomn4atiSmBbj-wfbjIUde2gpVsS1rhL9wJ_ NhE7dIokuA1w6VzDIR1XW6 svzU4J2Z0m466hYchjDGGcwVxg\&utm_content= 93555646\&utm_source=hs_email. Accessed 19 Aug 2020.

55. Centers for Disease Control and Prevention. Coronavirus Disease 2019 (COVID-19)-associated hospitalization surveillance network (COVID-NET). 2020. https://www.cdc.gov/coronavirus/2019ncov/covid-data/covid-net/purpose-methods.html. Accessed 19 Aug 2020.

56. Agency for Healthcare Research and Quality. Healthcare cost and utilization project (HCUP). www.http://hcupnet.ahrq.gov/. Accessed July 2020. 